\title{
RESIDUOS SÓLIDOS URBANOS E SUAS PROBLEMÁTICAS: O CASO DE PRESIDENTE VENCESLAU - SP
}

Yeda Ruiz Maria, Flávia Dias Martins, Jéssica Santos de Souza, Jéssica Tiemi Saito, Leticia Souza Primo, Mariana Ferreira Leme, Mariana Maia da Cruz Fernandes, Raísa de Lacerda Costa

Universidade do Oeste Paulista - UNOESTE. Curso de Arquitetura e Urbanismo, Presidente Prudente - SP. E-mail: leticia.sprimo@hotmail.com

\section{RESUMO}

O presente artigo é resultado de um projeto de pesquisa realizado para a disciplina de Planejamento Urbano III apresentado ao curso de Arquitetura e Urbanismo. Tem-se como objeto de estudo o município de Presidente Venceslau, interior do estado de São Paulo, que assim como as demais cidades do Oeste Paulista está de adequando atualmente as normas vigentes. Durante anos tais resíduos sólidos produzidos eram destinados á áreas verdes mais afastadas da malha urbana, devido a esta prática, houve o aparecimento de animais peçonhentos e transmissores de doenças, além de doenças causadas devido à degradação desse lixo exposto, assim como o risco de poluição do solo e dos lençóis freáticos. Assim, a construção de um aterro sanitário se justifica pela tentativa de solucionar tais problemáticas, garantindo a destinação correta aos resíduos, sem contaminar áreas verdes, garantindo uma melhor qualidade de vida à população.

Palavras-chave: Presidente Venceslau; Resíduos Sólidos, Áreas Verdes; Aterro Sanitário.

\section{URBAN SOLID WASTE AND ISSUES: THE CASE OF PRESIDENTE VENCESLAU - SP}

\begin{abstract}
This article is the result of a research project conducted for the discipline of Urban Planning III presented to the Architecture and Urbanism. Has as its object of study, the municipality of Presidente Venceslau, the state of São Paulo, as well as other cities of the west paulista is currently adapting the standards. For years such solid waste produced were intended will most remote areas of green urban fabric due to this practice, there was the appearance of poisonous animals, and disease, and caused due to the degradation of this exposed garbage diseases and the risk of pollution soil and groundwater. Thus, the development of a landfill is justified by the attempt to solve these problems, ensuring proper waste disposal, without contaminating green areas, ensuring a better quality of life for the population.

Keywords: Presidente Venceslau; Solid Waste, Green Areas; Landfill.
\end{abstract}




\section{INTRODUÇÃO E JUSTIFICATIVA}

Presidente Venceslau iniciou seu crescimento geográfico na década de 1920 com a vinda da Estrada de Ferro Sorocabana. Segundo Erbella (2006), o crescimento do município foi de modo radial em torno da Estação Ferroviária, principalmente nas direções norte e sul, contudo o desenvolvimento entre as duas porções foi diversificada, o que gerou um grave problema de segregação sócio espacial entre as porções, sendo a norte mais desenvolvida economicamente. De acordo com o IBGE (2010), o município apresenta uma área territorial de 756,742 km², uma densidade demográfica de 50,10 hab $/ \mathrm{km}^{2}$ e uma população estimada para 2013 de 39.265 habitantes.

Sabe-se que, segundo Coelho (2009), o conceito lixo nada mais é que todo produto de atividades humana que é considerado inútil e precisa ser descartado por um determinado motivo.

Portanto ao longo dos anos Presidente Venceslau teve um crescimento sem planejamento municipal adequado causando o surgimento de vazios urbanos, que são justamente áreas verdes em desuso, onde tais dejetos produzidos pela população vinham sendo descartados pela população de maneira inadequada transformando tais áreas verdes em verdadeiros lixões ao céu aberto:

Lixões: São depósitos de lixo sem nenhum tratamento. Esses depósitos causam poluição do solo, da água e do ar, além de atrair populações carente e desempregada, que passa a se alimentar dos restos encontrados no lixo. (Barra 2011, apud Macário, p. 12, 2007).

Diante de tal acontecimento, a Prefeitura Municipal de Presidente Venceslau designou uma área para construção de um aterro sanitário dentro das normas e legislações vigentes atualmente, na tentativa de solucionar tal problema de descarte indevido de resíduos sólidos e para evitar a degradação de áreas verdes que deveriam ser utilizadas para fins recreativos e de lazer comunitário.

Lima e Amorim (2011) pontuam que uma cidade precisa de áreas verdes que sejam utilizáveis, áreas que possam ser vivenciadas através do lazer:

As áreas verdes são importantes para a qualidade ambiental das cidades, já que assumem um papel de equilíbrio entre o espaço modificado para o assentamento urbano e o meio ambiente.

São consideradas como um indicador na avaliação da qualidade ambiental urbana, pois esses espaços livres públicos obrigatórios por lei, quando não são efetivados, interferem na qualidade do ambiente.

A falta de arborização, por exemplo, pode trazer desconforto térmico e possíveis alterações no microclima, e como essas áreas também assumem papel de lazer e 
recreação da população, a falta desses espaços interfere na qualidade de vida desta. (LIMA; AMORIM, 2011, p. 69).

Ou seja, essas áreas verdes que são consideradas grandes vazios urbanos seriam de grande utilidade para a população se não fossem utilizadas de maneira incorreta. O "lixão" acaba atuando nesta localidade como uma barreira segregativa, impedindo que a população desfrute de uma área que poderia ser potencialmente utilizada em prol do lazer comunitário. O mau cheiro, a sujeira, e a possibilidade de contrair doenças devido a animais peçonhentos são agentes que justificam tal barreira em relação a utilização desta área.

Deste modo o intuito deste artigo é relatar a forma como é feito atualmente o descarte dos resíduos sólidos urbano no município de Presidente Venceslau.

A metodologia utilizada para o levantamento de informações deste artigo ocorreu através de estudo de campo, levantamentos métricos, registros fotográficos, croquis, acompanhamento da elaboração e construção de uma das valas do aterro sanitário municipal e análises de áreas verdes com elaboração de tabelas explicativas. Foram realizadas também pesquisas documentais na Prefeitura Municipal de Presidente Venceslau e na Biblioteca Municipal, além de pesquisa bibliográfica em livros e artigos.

Vale pontuar que os levantamentos in loco foram analisados com orientação do docente responsável, apresentado como seminário em sala de aula e assim se constatou as informações apresentadas de introdução e as que se seguem.

\section{RESIDUOS SÓLIDOS E ÁREAS VERDES}

No município de Presidente Venceslau não há uma legislação que proteja as áreas verdes contra a degradação, como um Zoneamento Ambiental, evitando sua utilização inadequada pela população acentuando o desprezo pelo meio ambiente.

Um fato relevante é de que a cidade localiza-se exatamente entre duas Bacias Hidrográficas ${ }^{1}$ (Bacia Hidrográfica do Pontal do Paranapanema: UGRHI 22 - Unidade de Gerenciamento de Recursos Hídricos 22 e a Bacia Hidrográfica do Peixe: UGRHI 21 - Unidade de Gerenciamento de Recursos Hídricos 21), apresentando uma grande quantidade de rios e afluentes que surgem nestas áreas verdes que também precisam ser preservados para que não sejam contaminados com lixo urbano; dado que são estes rios e afluentes que abastecem a cidade.

Segundo a Prefeitura Municipal, até o ano de 2004 os resíduos sólidos produzidos na cidade de Presidente Venceslau eram depositados em uma propriedade privada denominada 
Fazenda Lagoa Seca, mais especificadamente, em valas rurais chamadas de "voçoroca" (erosões causadas por chuvas ou intempéries). Neste mesmo ano a Prefeitura Municipal foi notificada pelos proprietários da fazenda por esta não suportar mais o recebimento do lixo produzido pela cidade, iniciando assim a elaboração do projeto de construção do Aterro Sanitário para o município.

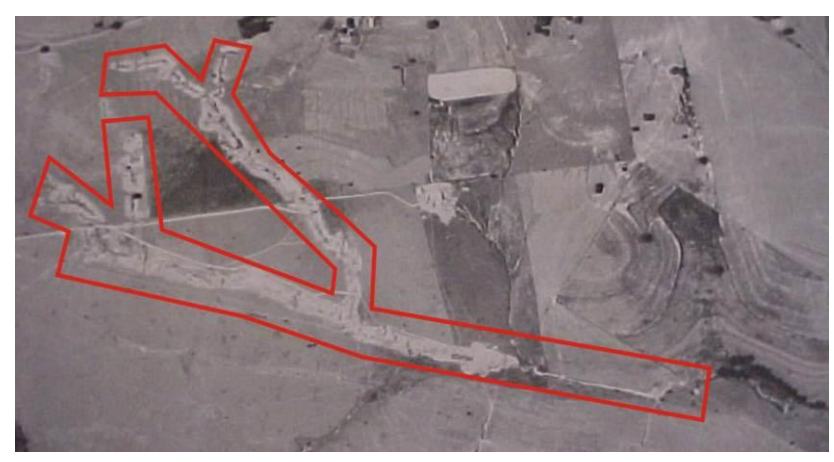

Figura 1. Delimitação da área do lixão na Fazenda Lagoa Seca.

Fonte: Prefeitura Municipal de Presidente Venceslau.

Para a elaboração do projeto foram feitos estudos de solo, vegetação, granulométria e compactação, direção dos ventos, entre outros, realizados por todo território de Presidente Venceslau, até encontrar uma área adequada, que fica a dois quilômetros da malha urbana da cidade e que, de acordo com esses estudos, agrediria menos a natureza. Depois de todo o estudo feito e das devidas aprovações nos órgãos competentes, o projeto foi colocado em pratica tendo sua conclusão no ano de 2006.

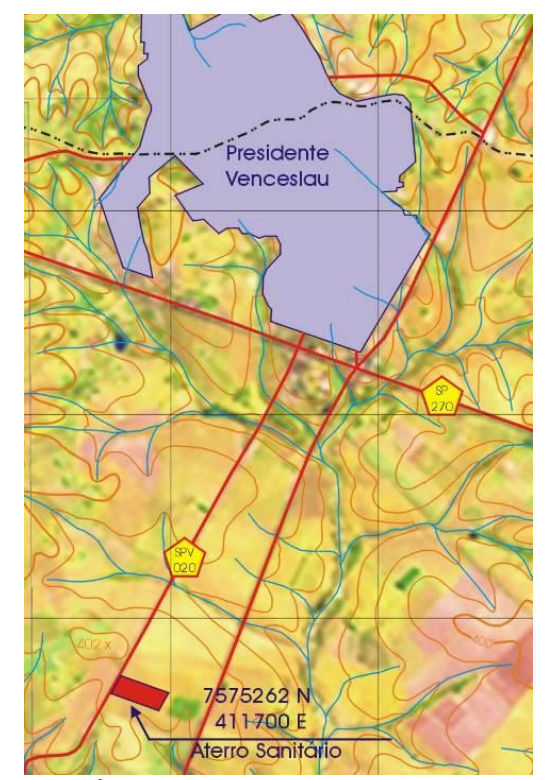

Figura 2. Localização do Aterro Sanitário em Presidente Venceslau - SP. Fonte: Prefeitura Municipal de Presidente Venceslau.

Este projeto foi elaborado em uma área de $98.000 \mathrm{~m}^{2}$, planejando-se a existência de seis valas para receber os resíduos, sendo construídas conforme necessidade. Atualmente encontra-se em uso a terceira vala, sendo a primeira que foi aberta já devidamente fechada, inclusive com 
vegetação na sua superfície, o que indica uma boa execução, e a segunda vala foi fechada no começo do ano de 2014. O local possui uma guarita de acesso, para que a entrada seja monitorada, evite o descarte de lixo inadequado e a presença de catadores. Possui ainda uma construção dotada de banheiro para os funcionários, área administrativa e um espaço onde funcionários de uma cooperativa separam o lixo reciclável.

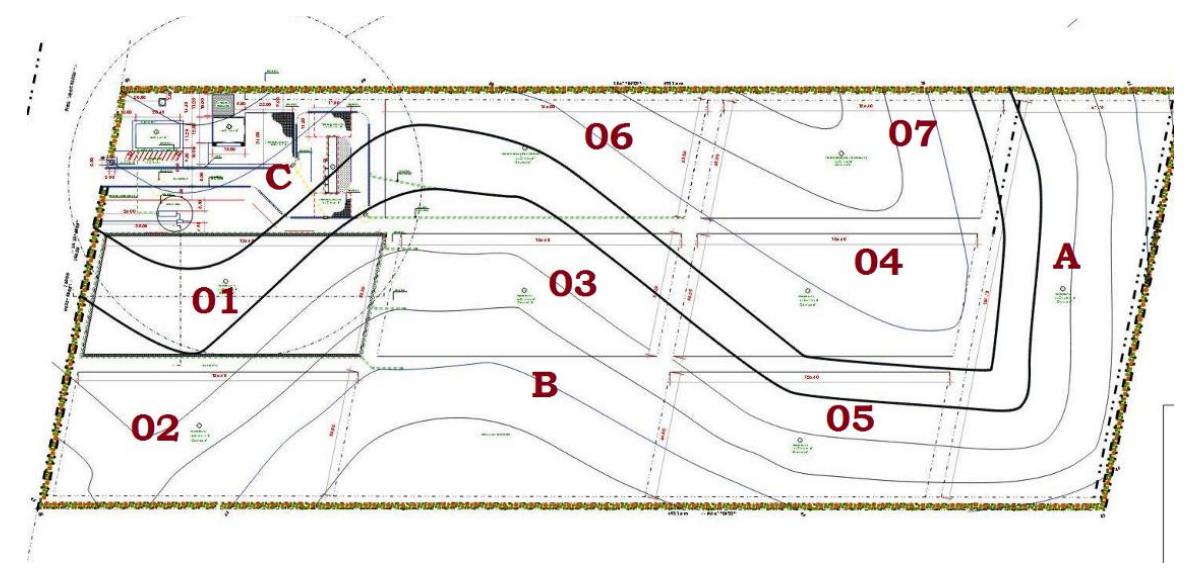

Figura 3. Projeto do Aterro Sanitário de Presidente Venceslau - SP Fonte: Prefeitura Municipal de Presidente Venceslau.

Todo o lixo reciclável não tem a mesma destinação do lixo descartável. Este é recolhido por funcionários da coleta seletiva do município, levado até o barracão do aterro sanitário e separado, posteriormente recebe o destino adequado.

Sobre a abertura da vala, esta ocorre primeiramente com a escavação do perímetro determinado em projeto, em seguida recebe um revestimento de uma manta geomembrana ${ }^{2}$, que protege o solo e ajuda na decomposição dos resíduos. Posteriormente é feito a abertura das chamadas "espinhas de peixe", por onde ocorre o escoamento do chorume produzido. Antes do depósito dos resíduos sólidos na vala é necessário que seja colocado uma camada de terra nesta, em seguida, conforme o lixo é depositado, esse processo da camada de terra acontece regularmente, segundo setor de planejamento da prefeitura municipal de Presidente Venceslau.

\section{DISCUSSÃO E CONCLUSÃO}

A pesquisa levantou questões á respeito da melhor maneira de se direcionar o lixo urbano produzido, porém, também nota-se que apesar da Prefeitura Municipal de Presidente Venceslau ter realizado e implantado um aterro sanitário municipal. Entretanto as observações in loco comprovam que ainda há quem insista em poluir áreas verdes, continuando a usá-las como lixões. Portanto, esta é uma questão de política ambiental, ou seja, a ausência de um plano diretor que possua um zoneamento ambiental que vise a proteção de áreas verdes que norteie o município através de leis que sejam fiscalizadas obrigando a população a cumprir o seu papel no descarte 
correto de resíduos sólidos, acaba gerando certa liberdade de ações inconsequentes que geram consequências gravíssimas ao meio ambiente.

Apesar do interesse da Prefeitura Municipal em melhorar o destino dos resíduos sólidos produzidos pelo município, é prioridade que a população também colabore para que o descarte destes resíduos seja realizado de maneira correta, sem afetar o meio ambiente, fazendo com que as áreas verdes estejam adequadas ecologicamente para fornecer lazer à população sem comprometer a saúde da mesma.

Com o auxílio de leis de proteção ambiental e também de educação ambiental para a população local, seria mais eficaz a ocorrência de uma preservação adequada e duradoura.

\section{REFERÊNCIAS}

Acervo Documento da Prefeitura Municipal de Presidente Venceslau.

AGETEC. Age Tecnologias. Apresenta a geomembrana. Disponível em: $<$ http://agetec.com.br/produtos/equipamentos/geomembranas-em-pead/> Acesso em: 08 ago. 2014.

BARRA, M. J. Um estudo sobre o lixo e reciclagem conceitos, fundamentos e características. 2011. 20f. Monografia (Curso de Geografia e Meio Ambiente - Bacharelado) - Universidade "Presidente Antônio Carlos" - UNIPAC, Barbacena.

CIDADES PAULISTAS. Apresenta os municípios que fazem divisa com Presidente Venceslau. Disponível em: <http://www.cidadespaulistas.com.br/prt/cnt/10-presprudente.htm> Acesso em: 23 mai. 2014.

COELHO, Pinto. Reciclagem e Desenvolvimento Sustentável, no Brasil. Belo Horizonte. Recoleo coleta e reciclagem de Óleos, 2009.

ERBELLA, I. Rabiscos Históricos de Presidente Venceslau. 1 ed. Presidente Venceslau: Artes Gráficas Pedriali, 2006.

IBGE. Instituto Brasileiro de Geografia e Estatística. Apresenta o município de Presidente Venceslau. Disponível em: <http://cidades.ibge.gov.br/painel/painel.php?codmun=354150> Acesso em: 17 mar. 2014.

LIMA, Valéria; AMORIM, Margarete Cristiane da Costa Trindade. A Importância das Áreas Verdes para a Qualidade Ambiental das Cidades. Formação (Online), v. 1, n. 13, 2011. 